\title{
O MENINO TÁ TODO TRISTE: UMA REFLEXÃO SOBRE A QUANTIFICAÇÃO UNIVERSAL NO PB
}

Roberta Pires de Oliveira*

\section{Aspectos da quantificação}

(1) João chegou ontem cedo.

(2) Um menino chegou ontem cedo.

* Universidade Federal de Santa Catarina. Agradeço o apoio do CNPq na forma de bolsa de Produtividade em Pesquisa.

1 A data se refere a uma edição em português. 
PIRES DE OLIVEIRA, R. O menino tá todo triste: uma reflexão...

Argumentos quantificados se compõem de um quantificador que, informalmente, determina a "quantidade" de indivíduos, e de um predicado, que delimita o grupo em que esses indivíduos devem ser buscados. É por isso que Ilari e Geraldi (1999, p. 19-20) afirmam que "utilizar na oração expressões quantificadas é de algum modo 'predicar a respeito de predicados'. Não admira que a quantificação fosse descrita por Frege como uma 'predicação de segunda ordem"”.

No exemplo (3), Todos, o quantificador, indica a totalidade de uma classe definida pelo predicado menino. Veja, no entanto, que (3) não é uma sentença, mas apenas um sintagma.

(3) Todos os meninos.

Em (4), temos uma sentença quantificada. Na visão mais recente, quantificadores não contam indivíduos, não indicam quantidade, mas estabelecem relações entre conjuntos.

(4) Todos os meninos são felizes.

Nesse exemplo, afirma-se que um certo domínio de entidades, no caso meninos, estabelece uma relação com um outro domínio, o conjunto dos felizes. Como o quantificador nessa sentença é todos, a relação entre o conjunto dos meninos e o conjunto dos felizes é de inclusão: o conjunto dos meninos está incluído no conjunto dos felizes. Na sentença em (2) a relação é de intersecção. Dessa maneira é possível interpretar a quantificação como um predicado que relaciona dois conjuntos. ${ }^{2}$

Essa perspectiva permite enxergar com mais clareza que a quantificação não é um fenômeno ligado exclusivamente ao sintagma nominal, o que facilita

2 Para uma apresentação mais detalhada da quantificação, ver Heim e Kratzer (1998), capítulos 5 e 6. 
entendermos que a quantificação não precisa ser expressa por um determinante dentro do sintagma nominal, mas pode ser realizada por outros elementos da sentença. Apresentamos abaixo um caso limite porque pode ser interpretado como uma quantificação no sintagma nominal ou como uma quantificação adverbial.

(5) Menino é feliz.

Em (5) não estamos falando de um indivíduo particular, mas fazendo uma generalização sobre uma classe de indivíduos. Certamente, e encontramos esta análise em manuais de lógica e introduções à semântica, é possível argumentar que a forma semântica de (5) é a mesma que a da sentença em (4). Essa análise aparece em Borges Neto (no prelo), por exemplo. Se esta é uma alternativa, é possível também considerar que (5) não diz exatamente o mesmo que (4); em outros termos, as condições de verdade dessas duas sentenças não são as mesmas. Esta linha de raciocínio pode ser encontrada em Krikfa et al. (1995) e também em Müller (2001).

Esses autores formulam a hipótese de que (5) expressa uma generalização que suporta exceções, ao passo que a sentença em (4) é uma sentença genérica que não admite exceções. A sentença em (5) não afirma, portanto, que há uma relação de inclusão do conjunto de meninos no conjunto de felizes. Se assim fosse, ela não admitiria exceções. A hipótese que esses autores desenvolvem, e que no momento parece ser a mais aceita pela comunidade de semanticistas que trabalham com línguas naturais, é de que a sentença em (5) está próxima semanticamente de (6):

(6) Geralmente menino é feliz.

(6) expressaria as condições de verdade de (5). Note que o uso do advérbio geralmente indica claramente a presença de exceções. Em (6) temos certeza de que a quantificação não ocorre no sintagma nominal, mas é produzida pelo advérbio. Seria, portanto, possível identificar dois tipos de quantificação, uma 
PIRES DE OLIVEIRA, R. O menino tá todo triste: uma reflexão...

ligada ao sintagma nominal e outra ligada a outros elementos, vamos dizer assim vagamente, da sentença.

Vejamos, agora, a sentença em (7):

(7) João fuma.

É possível argumentar que a sentença em (7) é uma sentença quantificada, embora não haja aparentemente nenhum quantificador presente. No PB, quando usamos sentenças como (7), não estamos falando de um evento particular em que João fuma, mas sobre um hábito de João. Trata-se, portanto, de uma generalização sobre o comportamento de João. Nesse caso, não há como creditar a noção de quantificação ao sintagma nominal, afinal João refere-se a um indivíduo particular, mas tampouco a um advérbio. De onde, então, tiramos a idéia de que fumar é um hábito de João, que fumar é, por assim dizer, uma generalização a respeito do comportamento de João? A quantificação parece estar, nesse caso, ligada à morfologia do verbo: o presente do indicativo no PB expressa não o tempo presente (a coincidência entre momento de fala e momento do evento), mas aspecto. $^{3}$ A morfologia contribui, assim, indicando uma quantificação e a sentença em (7) teria uma estrutura semelhante a (8):

(8) Geralmente João fuma.

\section{Quantificação-D e quantificação-A}

Partee (1995) distingue a quantificação-D da quantificação-A. Na quantificação-D, de determinante, o quantificador ocorre na posição sintática

3 O presente do indicativo pode indicar tempo presente em contextos muito específicos, por exemplo, numa enumeração de eventos. 
de determinante; nos limites, portanto, do sintagma nominal, como nos exemplos em (2) e (4). A quantificação-A, de aspectual, adverbial, é pré-teoricamente definida como toda quantificação que não é quantificação-D. Nas palavras da própria autora, "A para o conglomerado de Advérbios, Auxiliares, Afixos, e Ajustadores de Estrutura-Argumental"4 (1995, p. 544). As sentenças (5), (6), (7) e (8) são exemplos desse tipo de quantificação. Sem dúvida, essa categoria precisa ser melhor compreendida; o importante, por enquanto, é notar o contraste entre esses dois tipos de quantificação.

Várias são as questões suscitadas pela distinção entre quantificador-D e quantificador-A. Uma delas, que não será objeto de discussão neste artigo, diz respeito à chamada Hipótese do $\mathrm{SN}$-quantificado Universal proposta por Barwise e Cooper (apud Partee, 1995) que, interpretada em sua versão forte, prediz que em todas as línguas naturais os sintagmas nominais são quantificadores generalizados.

Toda lingual natural tem constituintes sintáticos (chamados de sintagmas nominais) cuja função semântica é expressar quantificação generalizada sobre o domínio de discurso. ${ }^{5}$ (p. 542)

Vários trabalhos têm procurado mostrar que o universal acima não está correto. Aparentemente (ver em especial os artigos de Partee e Jeniek em Bach et al., 1995), há línguas em que não há sintagmas quantificados, mas apenas sintagmas que ou indicam um indivíduo ou uma propriedade. Nessas línguas só há quantificação-A, isto é, a quantificação é feita exclusivamente por afixos, advérbios etc. Baseado nesses dados empíricos, e no fato de que não há língua sem quantificação-A, essa linha de pesquisa tem adotado como estrutura básica a estrutura atribuída a quantificação-A e a estendido para a quantificação-D. Há, assim, no momento, duas descrições da estrutura semântica do sintagma nominal em competição.

4 Tradução minha: "A for the cluster of Adverbs, Auxiliaries, Affixes, and Argument-Structure adjusters."

5 "Every natural language has syntactic constituents (called noun phrases) whose semantic function is to express generalized quantifiers over the domain of discourse". 
PIRES DE OLIVEIRA, R. O menino tá todo triste: uma reflexão...

\section{Estruturas}

$\mathrm{Na}$ visão dos quantificadores generalizados, a estrutura de sentenças quantificadas é a seguinte:

(9) $\quad[\mathrm{D}(\mathrm{A})](\mathrm{B})$.

De acordo com ela, a sentença em (4) receberia a seguinte interpretação:

(10) $[$ todo (Menino) $]$ (Alegre).

Todo está atuando como um determinante (D) do predicado Menino. Ele é uma função que toma um conjunto, o dos alegres, e projeta este conjunto numa família de conjuntos, aquela que define meninos. A sentença é verdadeira se ser alegre pertencer ao conjunto dos conjuntos que define meninos. ${ }^{6}$

Aparentemente, não é muito simples aplicar essa estrutura para descrever sentenças como (6). A literatura tem proposto uma estrutura mais plana para dar conta desse tipo de sentença, algo como:

(11) Geralmente ((Menino x) (Feliz x)).

Este tratamento, conhecido como Tratamento Relacional do determinante, parte da hipótese de que a estrutura de sentenças quantificadas seria:

6 Para uma visão menos superficial dos quantificadores generalizados, ver o capítulo 9 de Chierchia e McCornnell (1996). 
Essa estrutura pressupõe que em algum nível temos uma estrutura tripartite consistindo de um quantificador e dois predicados de um lugar denotando conjuntos de indivíduos, ${ }^{7}$ sendo representada graficamente por:

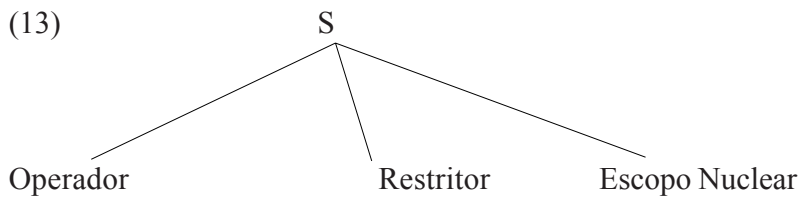

Heim (apud Partee, 1995) propõe tratar os quantificadores determinantes como tendo a mesma estrutura que os quantificadores adverbiais. Nessa linha, tanto a sentença em (4) quanto a sentença em (6) teriam a mesma estrutura, representada abaixo:

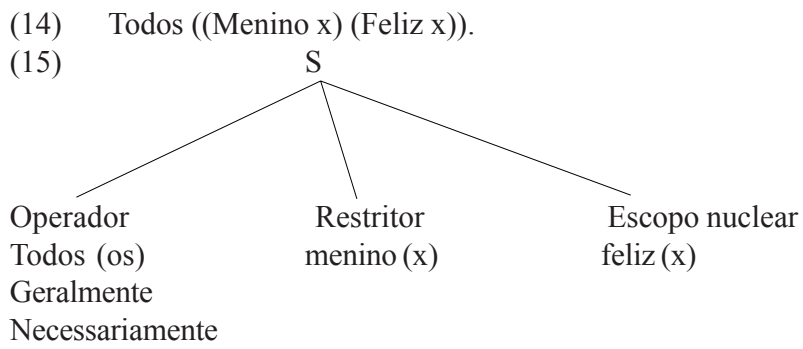

7 Estou falando informalmente em termos de conjunto, já que hoje em dia muitos semanticistas preferem trabalhar com a noção de reticulado. Sobre reticulados, ver Wachowicz (1997). 
PIRES DE OLIVEIRA, R. O menino tá todo triste: uma reflexão...

Nesse caso, o quantificador indica uma relação entre conjuntos. Todos estabelece que o conjunto dos meninos está incluído no conjunto dos felizes.

\section{O todo em sentenças com sintagma definido singular no PB}

São várias, portanto, as discussões teóricas que a pesquisa sobre quantificação enfrenta; em parte as soluções desses problemas dependem de análises empíricas das línguas naturais. Não há dúvidas de que o português brasileiro é um exemplo de língua que tem tanto quantificação-D quanto quantificação-A. Já mostramos vários exemplos de cada um desses casos. Gostaríamos, neste texto, de refletir mais detalhadamente sobre um caso que nos parece bem curioso para, a partir dele, repensar a própria distinção entre os dois tipos de quantificação. Trata-se do caso do todo em sentenças com sintagma nominal definido singular.

Reflita sobre o seguinte par de sentenças. A questão é: será que em ambos os casos a contribuição semântica do todo é a mesma? Será que a distinção entre quantificação-A e quantificação-D tem respaldo nesse caso?

(16) O menino todo tá machucado. ${ }^{8}$

(17) O menino tá todo triste.

É já conhecido na literatura o fenômeno da flutuação do quantificador. ${ }^{9}$ Com relação ao quantificador universal no $\mathrm{PB}$, a flutuação é possível somente se o sintagma for encabeçado por um artigo definido. Como mostramos em Pires de Oliveira (2002a; 2002b), ela não é possível com o sintagma nu:

8 Como veremos daqui a pouco, a posição do quantificador não parece ser aleatória. Vale notar que o quantificador flutua nesse tipo de sentença.

9 Ver Kato e Nascimento (1996) para uma análise da flutuação do quantificador universal plural. 
(18) a. Todo o menino está machucado.

b. O menino todo está machucado.

c. O menino está todo machucado.

(19) a. Todos os meninos estão machucados.

b. Os meninos todos estão machucados.

c. Os meninos estão todos machucados.

(20) a. Todo menino é feliz

b. * Menino todo é feliz.

Um primeiro aspecto a ser notado é que a flutuação do quantificador não tem o mesmo comportamento nos exemplos em (16) e (17). Há um contraste de aceitabilidade entre (17) e as sentenças abaixo:

(21) * Todo o menino tá triste.

(22) * O menino todo tá triste.

A sentença em (17) é ótima, enquanto que as sentenças (21) e (22) são, no mínimo, estranhas. Esse contraste simplesmente não ocorre com a sentença em (16), como é possível verificar em (18), embora a posição preferencial pareça ser pós-nominal. Como explicar este fato? A hipótese de que o todo é um determinante em (16) ao passo que em (17) é um advérbio que estaria atuando no sintagma verbal é um caminho de explicação, que, certamente, favorece a manutenção da distinção entre quantificação-D e quantificação-A. Ele será explorado adiante.

Uma segunda questão refere-se à interpretação de (16) e (17). Vamos nos deter nesse ponto, porque ele é a nossa entrada para discutirmos a pertinência da distinção. 


\section{Interpretação}

É possível supor que a interpretação mais pertinente de (16) seja a seguinte: o menino está machucado em todas as suas partes. ${ }^{10}$ Em Pires de Oliveira (2002a; 2002b), ao analisar as diferentes configurações dos sintagmas quantificados universalmente no $\mathrm{PB}$, é sugerido que em sentenças em que o sintagma quantificado é encabeçado por um artigo definido singular, como em (16), o artigo definido indica que a expressão nominal refere-se a um indivíduo em particular. Nessa descrição indivíduos são entendidos como um reticulado. O quantificador relaciona o conjunto de partes desse indivíduo ao conjunto indicado pelo predicado. A estrutura seria então a seguinte:

(23) Todo (Parte de indivíduo (x ,y)) (Predicado x).

O quantificador indica, nesse caso, uma inclusão de conjunto: o conjunto das partes está incluído em um outro conjunto. Note que estamos adotando a visão tripartite.

Esta análise explica não apenas os sintagmas universais definidos singulares no PB, mas também uma sentença como (24), que é a maneira usual de expressar quantificação no PE e, aparentemente, também em certos dialetos do Brasil:

(24) Toda a mulher tem útero.

Nesse caso, mulher deve ser considerado um indivíduo, talvez um indivíduo espécie como sugere Müller (2001), e recebe a mesma interpretação esquematizada em (23). Ela pode, ainda, explicar um caso curioso no PB:

10 Evidentemente, estamos falando sobre a semântica da sentença. A questão sobre se de fato o menino está mesmo machucado em todas as suas partes, embora pertinente e interessante, não pode ser desenvolvida no âmbito deste artigo. 
Nesse caso, o nome comum, núcleo do sintagma nominal, é um coletivo. Embora este não seja o tópico deste artigo, é possível entender que molecada é o nome de um grupo, um indivíduo plural, que funcionaria, assim, como um reticulado.

A hipótese que estamos admitindo entende que o artigo definido determina um indivíduo específico que é tomado como um conjunto de partes (um reticulado). O quantificador inclui esse indivíduo tomado em partes em outro conjunto. Vamos imaginar que esta descrição está na direção certa.

Ela simplesmente não pode ser aplicada a sentenças como (17), já que com ela não estamos afirmando que todas as partes do menino estão tristes, até porque o predicado ser triste não se aplica a partes de um indivíduo; ele indica estados em que seres animados podem estar. Note que (16) pode ser parafraseada por (26), mas (27) não é paráfrase de (17):

(26) Todas as partes do menino estão machucadas.

(27) * Todas as partes do menino estão felizes. ${ }^{11}$

É no mínimo estranho afirmar que as partes de um menino estejam tristes. ${ }^{12}$ Poder-se-ia supor que a estrutura da sentença em (17) fosse a mesma de (16), só que ao invés de estarmos falando sobre as partes "concretas", físicas, de um indivíduo, estaríamos falando de suas partes não concretas, quiçá psíquicas. Estaríamos, talvez, diante de uma metáfora, no sentido da semântica cognitiva. Essa, no entanto, não pode ser a explicação porque, em primeiro lugar, a sentença em (27) parece simplesmente não capturar a interpretação mais intuitiva da sentença em questão, mesmo se interpretamos partes como partes psíquicas. Usamos sentenças como (17) quando queremos afirmar que o menino está muito

11 Utilizamos o ponto de exclamação para indicar que a interpretação não é adequada, mas a sentença também é estranha, daí o asterisco.

12 Claro que este uso é sempre possível, mas ele provoca estranhamento. 
PIRES DE OLIVEIRA, R. O menino tá todo triste: uma reflexão...

triste. Se for isso, então aparentemente estamos, ao usar (17), afirmando algo sobre a intensidade do estado de tristeza em que o menino se encontra.

Em segundo lugar, tal hipótese não explica sentenças como (28), que, no entanto, parecem exibir a mesma estrutura e interpretação de (17).

(28) O centro está todo agitado.

Nesse caso, não cabe falarmos sobre partes não físicas. Discutiremos, mais adiante, a interpretação dessa sentença; por ora basta mostrar que a hipótese da metáfora não ajuda. Essa hipótese tampouco explica a seguinte sentença que ouvi ainda há pouco:

(29) Ele está todo atrasado.

Intuitivamente, o todo em (17), em (28) e em (29) indica a intensidade de um certo estado. Se for esse o caso, e é essa a melhor hipótese na nossa compreensão, então o quantificador não estaria atuando no sintagma nominal, mas estaria próximo de um uso adverbial. Este seria, portanto, um exemplo de quantificação-A.

Vamos então supor que em (16) temos um exemplo de quantificação-D, cuja interpretação demos em (23), e que em (17) temos um caso de quantificaçãoA. Já vimos que elas diferem não apenas com relação à interpretação, mas também quanto à possibilidade de flutuação do quantificador. Que interpretação atribuir a esse todo-A?

\section{O todo adverbial}

Se compararmos os pares de sentenças abaixo, veremos que a posição do quantificador parece não ser aleatória: em (30) ela faz parte do SN, em (31) do $\mathrm{SV}$. Este fato explicaria porque o quantificador adverbial não tem as mesmas 
possibilidades de flutuação do quantificador determinante. Deveria haver, então, diferença de interpretação entre elas. E de fato há, ainda que muito sutil.

(30) A criançada toda tá feliz.

(31) A criançada tá toda feliz.

O predicado ser feliz não pode se aplicar a partes de um indivíduo específico, a menos que este seja um coletivo, como é o caso de (30). Nesse caso, estamos afirmando que todas as partes do reticulado (ou grupo) nomeado por criançada, ou seja, todas as crianças, está incluído no conjunto dos felizes. Em (31), no entanto, esta não é a única possibilidade de interpretação, embora ela possa ocorrer dada a possibilidade de flutuação do quantificador. Outra possibilidade de leitura é de que não estamos falando sobre as crianças, mas sobre a intensidade da felicidade. (30) seria verdadeira numa situação em que a felicidade de cada um é "normal", enquanto que nessa situação (31) seria falsa. (30) seria falsa, ao menos, em termos estritamente semânticos, se houvesse uma criança infeliz, ao passo que (31) não seria necessariamente falsa, desde que a criançada estivesse bastante feliz.

O mesmo contraste está presente em:

(32) O centro todo está agitado.

(33) O centro está todo agitado.

Enfatizando, a posição do quantificador não parece ser aleatória. Mais uma vez, em (32) ele está dentro do sintagma nominal (na posição pós-nominal, que parece ser a preferencial no PB); em (33), ele está no sintagma verbal. É possível afirmar que em (32) estamos falando sobre as partes que compõem o centro e atribuindo a cada uma delas a propriedade de estar agitada, ao passo que em (33), além dessa interpretação, podemos estar afirmando que a agitação do centro é grande, embora ela não precise ocorrer em todas as suas partes. (33) 
PIRES DE OLIVEIRA, R. O menino tá todo triste: uma reflexão...

é verdadeira no caso em que apenas a praça central da cidade está agitada, desde que essa agitação seja intensa. Nesta situação, (32) seria falsa.

Nessa linha de raciocínio o quantificador todo- $A$, presente nas sentenças (17), (31) e (33), incide não dentro do sintagma nominal, mas sobre a propriedade que aparece no sintagma verbal, marcando sua intensidade. Nesse caso, faz sentido pensar nesse todo como estabelecendo uma relação paradigmática com advérbios e expressões adverbiais como muito, meio, um pouco, totalmente:

$\begin{array}{ll}\text { O menino está } & \text { todo feliz. } \\ & \text { muito } \\ & \text { meio } \\ & \text { um pouco } \\ & \text { totalmente }\end{array}$

Há, pois, argumentos fortes para sustentar uma distinção entre o todo em (16) e o todo em (17). Note que os outros advérbios tampouco podem ocorrer dentro do SN:
a. * Todo o menino está feliz.

b. Muito o menino está feliz.

Poder-se-ia argumentar contra essa hipótese trazendo a tona o problema da concordância nominal, já que advérbios deveriam ser invariáveis. Como sabemos, o todo é variável:

(36) A menina tá toda feliz. 
Esse, no entanto, não parece ser um argumento forte porque, por um lado, historicamente não havia concordância em contextos como a sentença em (17); ${ }^{13}$ por outro, em vários dialetos atuais, advérbios como meio fazem concordância (Maria está meia cansada) a despeito da ojeriza que essas sentenças causam aos defensores da norma culta. Talvez a concordância nominal seja um fenômeno superficial.

Apresentamos em (23) uma proposta de descrição da semântica do todo determinante; o que dizer do todo adverbial? Se nosso raciocínio está correto, (23) não explica o todo- $A$. Uma linha de solução para o problema é, nos parece, entender que este todo indica a quantidade da intensidade. Ele seria, assim, um intensificador na acepção ainda pré-teórica apresentada em Ilari (1990). Embora o todo não exiba o mesmo comportamento que o muito, o intensificador prototípico (por exemplo, o todo não pode ocorrer como núcleo do $\mathrm{SN}$ ), eles certamente realizam a mesma tarefa semântica, tal qual descrita pelo autor:

O elemento comum que todos os intensificadores compartilham é o de marcarem, de maneira absoluta ou relativa, localização num parâmetro que se associa a uma propriedade ou ação para representá-la como variável... (1990, p. 91)

Seguindo essa linha de raciocínio aberta por Ilari, vamos apresentar uma hipótese de descrição que irá corroborar a necessidade da distinção entre quantificador-A e quantificador-D porque mostrará que a semântica do todo não é a mesma nesses dois casos. A idéia básica é de que o todo- $A$ é um intensificador que atua sobre a propriedade expressa no sintagma verbal. Aparentemente, mas uma pesquisa mais profunda é necessária, todo- $A$ só se combina com predicados que aceitam gradação. A sentença abaixo parece estranha porque a propriedade ser morto não admite graus:

O menino tá todo morto.

13 Agradeço essa dica a Emílio Paggotto. 
Já a tristeza (como todos sabemos!) pode ser mais ou menos intensa. Os chamados adjetivos intra-sectivos (ou intensionais) ${ }^{14}$ funcionam estabelecendo seções dentro de um conjunto dado ou explicitamente ou discursivamente. Por exemplo, a sentença abaixo:

(38) João é alto.

Ao ser interpretada, estabelece um conjunto de comparação; sem qualquer outra informação, supomos que este conjunto seja o das pessoas normais. Sendo este o parâmetro, a sentença indica que João situa-se na seção dos altos. Nessa linha de raciocínio, o todo- $A$ dependeria de estabelecermos, para a interpretação da sentença, um conjunto seccionado em graus de intensidade. Por exemplo, o conjunto de entidades tristes seria, ao ser modificado pelo todo, seccionado em graus:

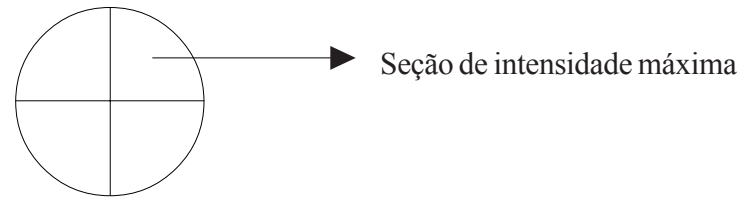

Ao afirmar uma sentença como (17), coloca-se o menino na seção em que a intensidade da tristeza é máxima. Assim, ainda de maneira intuitiva, o todo-A "coloca" o conjunto denotado pelo SN sujeito na seção de maior intensidade do conjunto denotado pelo SV.

Essa análise explica uma sentença como:

(39) João trabalha todo feliz.

14 Ver capítulo 4 de Heim e Kratzer (1998) e, para o PB, ver Borges Neto (1991). 
A sentença em (39) é ambígua porque podemos estar falando de um evento particular de trabalho de João ou do seu modo habitual de trabalhar. Vamos admitir que estamos diante do primeiro caso, a semântica dessa sentença seria algo como:

(40) O evento de trabalho de João está inserido no estado de felicidade na seção de maior intensidade.

Em outros termos, o quantificador todo- $A$ secciona o conjunto dos estados de felicidade em graus de intensidade e insere o evento de João na seção de estados de felicidade máxima.

Se esta análise estiver correta, então a diferença entre as sentenças (29) e (30) pode ser apresentada como a seguir:

(41) (Parte da criançada $\mathrm{x}$ ) está incluído em (Estado de felicidade $\mathrm{x}$ ).

(42) (Parte de criançada $\mathrm{x}$ ) (todo (Estado de felicidade $\mathrm{x}$ )).

A estrutura em (42) é, com certeza, uma primeira tentativa de estabelecer a semântica da sentença (31). É muito provável que o SN em (31) seja um singular nu e, nesse caso, a semântica da sentença deveria ainda incluir um operador genérico. Esse movimento justificaria nossa afirmação de que a sentença em (31) comporta exceções porque o quantificador todo estava atuando no SV e não no SN. Portanto, na interpretação que estamos interessados, afirma-se que a maior parte das crianças está num estado de felicidade máxima, mas não necessariamente todas.

A mesma explicação pode ser facilmente aplicada ao par (32) e (33). 


\section{Conclusão}

Este artigo é um primeiro passo na tentativa de refletir com mais acuidade sobre a distinção entre quantificação-A e quantificação-D a partir de um caso particular do $\mathrm{PB}$, o uso de todo em sentenças encabeçadas por um SN definido singular. Mostramos que o todo, nesse tipo de sentença, pode tanto expressar uma quantificação do sintagma nominal quanto uma quantificação adverbial. Indicamos que essa diferença é marcada pela posição em que o quantificador se encontra e que ela é corroborada pelas diferenças com relação à flutuação. Se o quantificador estiver atuando dentro do sintagma nominal, ele quantifica sobre partes de um indivíduo e inclui este conjunto de partes no conjunto denotado pelo SV. Nesse caso, o quantificador pode ocupar várias posições na sentença; ele tem flutuação livre.

O todo pode, no entanto, atuar no sintagma verbal. Nesse caso, ele indica a intensidade da propriedade expressa pelo SV. As possibilidades de flutuação são restritas. Sugerimos que a semântica do todo-A é de um intensificador que secciona o conjunto denotado pela propriedade expressa pelo SV em graus e ele "coloca" o conjunto denotado pelo SN na seção em que o grau de intensidade é máximo. Se essa hipótese estiver correta, então o todo$A$ e o todo- $D$ atuam semanticamente de maneira distinta, o que corrobora a necessidade dessa distinção.

\section{RESUMO}

A discussão sobre o quantificador todo em sentenças do Português Brasileiro (doravante $\mathrm{PB}$ ) com $\mathrm{SN}$ definido singular na posição de sujeito, como em $O$ menino tá todo triste, visa descrever uma particularidade semântica do PB e utilizá-la para esclarecer e questionar a pertinência da distinção formulada inicialmente por Partee (1995) entre quantificação-A e quantificação-D. A tese central é de que a distinção é pertinente porque a semântica do todo- $A$ e do todo- $D$ não é a mesma.

Palavras-chave: Semântica formal, quantificação, advérbios. 


\begin{abstract}
The paper discusses the quantifier todo in Brazilian Portuguese (PB from now on) sentences which are composed out of a defined singular nominal phrase in subject position, as in $O$ menino tá todo triste. It aims at clarifying and questioning the necessity of the distinction, formulated by Partee (1995), between A quantifier and D quantifier, and concludes that such a distinction is pertinent because the semantics of todo- $A$ is not the same as the semantics of todo-D.
\end{abstract}

Key-words: Formal Semantics, quantification, adverbs.

\title{
REFERÊNCIAS
}

BACH, Emmon et al. Quantification in Natural Languages. Dordrect: Kluwer Academic Publishers, 1995.

BORGES NETO, José. Adjetivos. Predicados Extensionais e Predicados Intensionais. Campinas: Ed. da Unicamp, 1991.

. Semântica de modelos. In: MÜLLER, Ana Lúcia; NEGRÃO, Esmeralda V.; FOLTRAN, Maria José (Orgs.). Semântica formal. São Paulo: Contexto, 2003.

CHIERCHIA, Gennaro; McCONNELL-GINET, Sally. An Introduction to Semantics. Cambridge, MA: MIT Press, 1996.

FREGE, Gottlob. Lógica e filosofia da linguagem. Trad. e Sel. de: Paulo Alcoforado. São Paulo: Cultrix, 1978.

HEIM, Irene; KRATZER, Angelika. Semantics in Generative Grammar. Massachusetts: Blackwell, 1998.

ILARI, Rodolfo; GERALDI, João Wanderley. Semântica. São Paulo: Ática, 1999.

. Considerações sobre a posição dos advérbios. In: CASTILHO, Ataliba Teixeira

(Org.). Gramática do Português Falado. Campinas: Ed. da Unicamp, 1990. v. 1: A ordem, p. 63-142.

KATO, Mary; NASCIMENTO, Milton do. Preenchedores aspectuais e o fenômeno da flutuação dos quantificadores. In: CASTILHO, Ataliba Teixeira; BASÍLIO, Margarida (Orgs.). Gramática do Português Falado. Campinas: Ed. Unicamp, 1996. v. 4: Estudos Descritivos. p. 245-272. 
PIRES DE OLIVEIRA, R. O menino tá todo triste: uma reflexão...

KRIFKA, Manfred. et al. Genericity: an introduction. In: CARLSON, G. N.; PELLETIER, F. J. (Eds.). The Generic Book. Chicago: The University of Chicago Press, 1995.

MÜLLER, Ana. Genericity and the denotation of common nouns in Brazilian Portuguese. In: WEELER, Adam; KIM, Ji-Young (Eds.). The Semantics of Under-Represented languages in the America. U. Mass. Occasional Papers, Amherst, USA., n. 25, p. 72-80, 2001.

PARTEE, Barbara. Quantificational Structures and Compositionality. In: BACH, E. et al. (Eds.). Quantification in Natural Languages. Dordrecht: Kluwer, 1995. p. 541-601.

PIRES DE OLIVEIRA, Roberta. Aspectos da quantificação universal no PB. In: ENCONTRO DO GRUPO DE ESTUDOS LINGÜÍSTICOS, 51., 2002a, São Paulo.

PIRES DE OLIVEIRA, Roberta. Aspectos sintático-semanticos do quantificador universal no PB. In: ENCONTRO DA ASSOCIAÇÃO NACIONAL DE PÓS-GRADUAÇÃO E PESQUISA EM LETRAS E LINGÜÍSTICA, 17., 2002b, Gramado.

WACHOWICZ, Teresa. Uma semântica de reticulados para os plurais e os termos de massa. Curitiba, 1997. Dissertação (Mestrado) - USP. 